London, UK

limb@btinternet.com

Cite this as: BMJ 2021;374:n2201

http://dx.doi.org/10.1136/bmj.n2201

Published: 16 September 2021

\section{BMJ Awards 2021: Environmental sustainability and climate action team of the year}

\author{
Matthew Limb reports on projects to expand access to therapeutic gardening and to reduce the \\ effect of anaesthesia and other healthcare on climate change
}

Matthew Limb freelance journalist

\section{Signposting tool puts down strong roots-gardening4health Directory of Social and Therapeutic Horticulture}

"As a GP and keen gardener, I have long been aware of the benefits of gardening and horticulture for my own well-being, but more importantly for that of my patients," says Richard Claxton. Successive lockdowns during the pandemic have reinforced the value of gardening, he says, and awareness is growing. More organisations are now providing social and therapeutic horticulture, which gives help, support, and camaraderie to many, including the volunteers who often work for them. But these benefits are not always easy to access for people living with mental health problems, physical health problems, sensory impairments, learning disabilities, and other challenges, including loneliness and isolation.

Claxton found he didn't know what was available in his own area, Kent and Medway; nor did his patients or social prescribing colleagues. There was no central signposting resource. He created the online directory gardening 4 health-A Directory of Social and Therapeutic Horticulture in the UK, to "connect people" with their local schemes. So far it has included 405 different therapeutic gardens or organisations and has attracted 4000 visitors in just nine months. Claxton says he is thrilled to be able to highlight the benefits of social and therapeutic horticulture and further boost its momentum. "Every practice now has a social prescriber attached to them-and I've been helped by the National Association of Social Prescribers in publicising the website/directory among their members."

\section{Road to net zero-Greener Anaesthesia and Sustainability Project volunteers breathe new life into climate action}

"The climate crisis is a health crisis, and it is health systems that will yet again be on the front line," say anaesthetic registrars Jonny Groome and Hannah Lewis. They are part of the Greener Anaesthesia and Sustainability Project (GASP), founded in 2018 as a nationwide, non-profit, multidisciplinary movement to enact change in response to the climate crisis.

Groome works at Great Ormond Street Hospital in London and Lewis at Moorfields Eye Hospital. They say, "Health systems contribute $4.4 \%$ of carbon dioxide emissions worldwide, with anaesthesia and surgery being major contributors." GASP aims to reduce emissions from anaesthetic gases and single use items, promote recycling, and reduce energy use and drug waste. Since its creation, it has successfully implemented a range of carbon reduction projects in the UK. GASP volunteers work across four domains-education, advocacy, improvement, and consulting-with a committee of more than 40 members. A free-to-access GASP website provides educational resources, live webinars, and free consulting for NHS trusts (gaspanaesthesia.com).

This year sees the first national GASP conference, with global expert speakers and poster sessions. Groome and Lewis say that many changes made to protect staff and patients during the pandemic had "positive effects" on the environment. They are now working to encourage the use of telemedicine, reducing unnecessary patient journeys. "We are also working to maintain the increased uptake in local, regional, and sedation techniques (implemented to reduce aerosolization), as they have a lower carbon footprint to general anaesthesia."

\section{National nitrous oxide mitigation project -tackling planetary and occupational health threats}

Nitrous oxide is a potent greenhouse gas and ozone depleting substance. Efforts within NHS Lothian to reduce the total contribution of theatre nitrous oxide revealed that wastage from piped manifold systems is a far more important problem than that of persistent clinical usage. "The waste through leakages is both a threat to planetary and occupational health as leaks can expose staff to persistent levels of nitrous oxide," says Alifia Chakera, who is lead pharmacist for theatre and anaesthetics at NHS Lothian and a consultant in sustainable medicines management.

In January 2021, with the support of Centre for Sustainable Healthcare's environmental fellows, she launched the national Nitrous Oxide Project. It aims to provide a fuller understanding of the NHS's use of nitrous oxide-cylinder turnover versus true clinical usage. Its overall aim is to achieve zero emissions of N2O: mitigate system waste, encourage greener clinical practice, and assess and apply green technology where needed. Chakera says, "By 31 March 2021, 16 sites across the UK and the Republic of Ireland had reported that, on average, $95 \%$ of piped nitrous oxide was wasted, equating to 13.7 million litres annually (approximately 7500 flights from London to New York).”

This work is now embedded into the Greener NHS programme and is being promoted within the UK and Ireland with the support of the Association of 
Anaesthetists' environmental champions network. Chakera says if the mitigation approach is rolled out widely and rigorously it can allow the UK to "flatten nitrous oxide emissions in the next 5 years."

The environmental sustainability and climate action team of the year award is sponsored by BSI.

The winners of the environmental sustainability and climate action team of the year award will be announced at The BMJ Awards virtual ceremony on Wednesday 29 September 2021. For more information see https://thebmjawards.bmj.com 